\title{
Anorexia nervosa and food avoidance emotional disorder
}

\author{
J F HIGGS, I M GOODYER, AND J BIRCH
}

The Royal Manchester and Booth Hall Children's Hospitals, Manchester

SUMMARY A retrospective and longitudinal study was carried out on all children and adolescents who presented to a child psychiatry service over a period of 26 years to identify the nature, course, and outcome of cases meeting criteria for anorexia nervosa $(n=27)$. Two groups of the same age were identified for comparison, firstly those with food avoidance and emotional disorders $(n=23)$, and secondly those with emotional disorders but no symptoms associated with eating $(n=22)$. The results confirm previous reports that early onset anorexia nervosa shows a similar nature, course, and outcome to the adult disease. Being tall at presentation seems to be associated with a poor outcome. Self starvation of early onset may result in short stature in some cases.

There seem to be more boys among the group in whom the disease was of early onset than would be predicted from the sex ratio among adult patients. In addition boys with anorexia nervosa may have a better prognosis than girls. Children with food avoidance emotional disorders seem to have a worse prognosis than expected for childhood emotional disorders. They may represent a middle group between those with anorexia nervosa and those with emotional disorders but no symptoms associated with eating.

The occurrence of anorexia nervosa in childhood and early adolescence has been known for some time though it has generally been thought to be rare, particularly in prepubertal children..$^{1-3}$ Recently, however, there have been a number of reports that have suggested that some children and young adolescents who meet the diagnostic criteria for anorexia nervosa may be missed or diagnosed late ${ }^{4}$; that the nature, course, and outcome of the disorder in young people is similar to that of adult patients; and that self starvation of early onset may delay puberty and restrict subsequent physical growth, perhaps permanently. ${ }^{67}$

These studies indicate a number of clinical characteristics. The essential characteristics may be identified in children as young as 7 to 8; prepubertal cases do occur infrequently, the clinical picture in prepubertal children may present with varying degrees of emotional and behavioural symptoms; depression is commonly part of the presenting picture; and a larger number of boys may present in childhood than as adults.

In the one longitudinal study ${ }^{6}$ a poor prognosis was associated with: early age at onset, a long duration (more than eight weeks) in hospital, two or more admissions to hospital, depression at presentation, and certain adverse family factors-for example, one parent families, step families, and intergenerational families with three or more generations in the house.

In addition to those with classical anorexia nervosa, a number of children present to psychiatric clinics with symptoms associated with eating who are considered to have more general emotional disturbances. Most of these are preschool children although some are in middle childhood. Such cases are commonly classified as childhood emotional disorder (International Classification of Diseases (ICD) 9 code 313.0), occasionally as depression (ICD code 300 ) and, in the absence of other clear diagnostic criteria as neurotic eating disorder (ICD 9 code 307.5). At present we know little of the similarities or differences between these emotional disorders and anorexia nervosa.

A cross sectional and longitudinal study of cases presenting with anorexia nervosa, and emotional disorders with or without symptoms of food avoidance may provide further evidence about the nature, course, and outcome of disorders associated with food avoidance in young people.

\section{Patients and methods}

The study was carried out at the Royal Manchester 
and Booth Hall children's hospitals, which provide a district and regional service for the north west of England and have a university department of child and adolescent psychiatry as well as inpatient facilities for severely disturbed children and adolescents. All records from 1958 (the inception of the inpatient child psychiatry service) to 1984 were included in the study. The records were searched firstly for all cases who met the diagnostic criteria for anorexia nervosa as set out by Russell. ${ }^{8}$

These criteria were modified to include only those children in whom puberty was not complete and who exhibited behaviour which lead to a marked loss of body weight, or had a morbid fear of becoming fat, or had no evidence of menarche in girls or signs of secondary sexual characteristics in boys. These subjects were identified as the 'early onset anorexia nervosa group' as their disorder occurred in childhood or adolescence and they were prepubertal or were identified as having not completed puberty.

For each case two psychiatric comparison groups were identified who were the same age at referral. The first showed a disorder of the emotions in which food avoidance was a prominent symptom in the presenting complaint. The following criteria also had to be met for this group: a history of food avoidance or difficulty such as food fads or restrictions of at least one month; a failure to meet criteria for anorexia nervosa; and the absence of organic brain disease, psychosis, illicit drug abuse, or prescribed drug related causes.

The second comparison group comprised those patients who had disorders of emotions in which the main symptoms included anxiety, together with degrees of fearfulness and panic. Other symptoms such as misery and sadness, obsessionality, and hysterical phenomena could be present but did not dominate the clinical picture. The comparison cases consisted of the next case after the anorexic case who met the above criteria.

\section{DATA FROM CASENOTES}

The following data were collected from the casenotes:

(i) Body weight and height; expected body weight was used as a comparison between the clinical groups and taken from standardised centile charts and normal values for the general population. $^{9-11}$

(ii) The past medical and psychiatric history of the child including obstetric and perinatal problems and past developmental difficulties.

(iii) The presence of family adversity. This included medical and psychiatric disorders in nuclear family members, life events including family moves, permanent separations, and disruptions. Disruptive events were defined as those the effects of which were likely to have altered the families' status quo permanently.

(iv) Demographic characteristics and social circumstances at the time of presentation.

\section{FOLLOW UP DATA}

Cases of anorexia nervosa and food avoidance were traced through their general practitioners or the National Health Service register. A standardised interview routine was used to evaluate the patients' physical, mental, and social well being. ${ }^{2}$ The interview was carried out with the subject and provided for ratings in five areas: nutrition, menstruation, mental state, psychosexual development, and socioeconomic circumstances; these five areas received individual scores. A general outcome score may be calculated based on the previous six months' history of weight and menstrual function in girls and weight alone in boys. General outcome was rated on a 3 point scale: good, moderate, and poor adjustment. All subjects who participated in the follow up study had their height, weight, and pubertal state recorded.

Non-parametric, $\chi^{2}$ test, and Fisher's exact test were used to assess the significance of differences among the groups, as appropriate.

\section{Results}

A total of 8051 records were surveyed. Twenty seven children met the criteria for anorexia nervosa. Twenty three children with predominant (food avoidance) eating difficulties, and 22 with emotional disorders not associated with eating met the criteria for the comparison groups.

All casenotes were surveyed independently by two of the authors (JH and JB) who were unaware of each other's findings. The kappa coefficients ranged from 0.64 to 0.93 for the recorded information indicating satisfactory reliability.

CLINICAL AND BACKGROUND CHARACTERISTICS OF THE THREE GROUPS

The characteristics of the clinical groups are shown in table 1. Eight of 27 of the cases of anorexia nervosa $(30 \%)$ were boys. Percentage body weight was calculated and less than $80 \%$ body weight considered as indicating wasting. Nineteen of 27 $(70 \%)$ of those with anorexia nervosa were significantly wasted at the time of presentation compared with six of $19(32 \%)$ of the food avoidance group $\left(\chi^{2}=6 \cdot 76, \mathrm{df}=1, \mathrm{p}<0.01\right)$. Four of eight $(50 \%)$ of the boys and 15 of $19(79 \%)$ of the girls with anorexia nervosa were wasted (NS). Of the wasted 
Table 1 Comparison of characteristics recorded in the casenotes of the clinical groups at the time of presentation to psychiatric services

\begin{tabular}{llll}
\hline & $\begin{array}{l}\text { No with } \\
\text { anorexia nervosa } \\
(n=27)\end{array}$ & $\begin{array}{l}\text { No with } \\
\text { eating difficulties } \\
(n=23)\end{array}$ & $\begin{array}{l}\text { No with } \\
\text { emotional disorders } \\
(n=22)\end{array}$ \\
\hline Sex F:M (\%) & $19: 8(70: 30)$ & $18: 5(78: 22)$ & $13: 9(59: 41)$ \\
Mean age (range) at onset (years) & $12(8-16)$ & $10(8-14)$ & $10(7-14)$ \\
No (\%) below 80\% expected body weight for height & $19(74)(15 \mathrm{~F}: 4 \mathrm{M})$ & $6(32)(\mathrm{n}=19)$ & $0^{*}$ \\
No (\%) at 3rd centile or less for height and weight & $3(11)$ & $3(16)(\mathrm{n}=19)$ & 0 \\
No (\%) 'middle class' & $14(54)$ & $5(23)$ & $4(18)^{*}$ \\
No (\%) giving history of illness in the family & $9(38)$ & $11(52)$ & $15(68)^{*}$ \\
No (\%) giving history of one or more disruptive life events & $13(52)$ & $8(36)$ & $5(23)^{*}$ \\
No (\%) of children with history of obsessionality & $16(59)$ & $4(17)$ & $2(9) \dagger$ \\
\hline
\end{tabular}

${ }^{*} \mathrm{p}<0.05 ; \mathrm{tp}<0.001$.

subjects three of $19(16 \%)$ in the group with anorexia nervosa compared with half the food avoidance group had heights below the 3rd centile at the time of presentation $(\mathrm{p}<0.05)$.

Comparison of the rest of the data from the casenotes indicated the following significant differences between the groups: cases of anorexia nervosa were significantly more likely than either of the other two clinical groups to have a middle class background $(p<0.05)$; cases of anorexia nervosa were significantly more likely to have a past history of obsessionality recorded at the time of presentation $(p<0.05)$, and there was a suggestion in the notes that disruptive life events that permanently altered the families' status quo were significantly more likely in anorexia nervosa families than in the other two groups $(\mathrm{p}<0.05)$.

By contrast, however, a history of medical illness in the family that had required hospital treatment was significantly more likely in emotionally disordered children with no eating symptoms than the group with anorexia nervosa $(p<0.05)$. No such difference existed, however, between the anorexia nervosa and food avoidance groups, or the food avoidance and emotionally disordered groups.

There were no significant differences among the three clinical groups in family size, the presence of step parents, three or more generations in the same house, or the proportion of adults or siblings with recorded psychiatric disorders, neither were there any significant differences in the obstetric, perinatal, or developmental histories among the three groups.

\section{OUTCOME OF THE FOLLOW UP STUDY}

A follow up study was carried out on the 50 children with anorexia nervosa or eating disorders. A letter was written to each family requesting an interview with the identified subject and the parents.

The mean follow up time from discharge from hospital for anorexia nervosa patients was $5 \cdot 2$ years (median 3 years, range 1-26) and for food avoidance cases 6.5 years (median 5 years, range 1-17). The mean age at follow up was $19.3(12-42)$ years for the cases with anorexia nervosa and 18.7 years (11-23) for those with food avoidance.

At the time of follow up eight of $27(30 \%)$ anorexia nervosa cases and six of $23(21 \%)$ emotionally disordered cases were less than 16 years old.

All subjects were traced and contacted. Two children had died by the time of follow up, both from the food avoidance group; they were a girl with persistent psychogenic vomiting who had a cardiac arrest, and a boy who was subsequently diagnosed as having muscular dystrophy. Two further boys who had been diagnosed as having anorexia nervosa were found to have physical disease 24 months or later than the original presentation; one had coeliac disease and the other myasthenia gravis. We did not, however, have positive evidence at follow up that their anorexic illnesses had been misdiagnosed, and they were both therefore included in the follow up study.

There was considerable reluctance in both groups on the part of the parents and the subjects to participate in the follow up interviews. In 13 cases (26\%) direct interview and examination were refused. Subjects were therefore seen and interviewed in 35 of 50 of the cases $(70 \%)$. Parents were interviewed in two other cases. In four further cases information was obtained by letter indicating the weight and menstruation pattern over the past six months; this information was used when comparing general outcome between anorexia nervosa and food avoidance groups at follow up. Only results from the direct interviews were used for the comparison of outcome at follow up on all five Morgan-Russell scales. ${ }^{12}$ Outcome scores on the Morgan-Russell scales for subjects and parents (that is 35 pairs) obtained at interview showed good agreement (rho $=0.82 \mathrm{p}<0.001)$. 
Outcome and gender-The general outcome according to gender is shown in table 2 . In the anorexia nervosa group, 16 of 19 of the girls $(84 \%)$ and seven of eight of the boys $(88 \%)$ were interviewed. Of these, half of the girls were rated as having a poor outcome compared with one of eight of the boys $(12.5 \%)(p=0 \cdot 08)$. In the food avoidance group 15 of 18 of the girls $(83 \%)$ and three of five of the boys $(60 \%)$ were interviewed. Of these three of 15 of the girls $(20 \%)$ were rated as having a poor outcome and none of the boys (NS).

At the time of follow up one girl in the anorexia nervosa group met the criteria for food avoidance, and three girls in the emotionally disordered group met the criteria for anorexia nervosa. No such diagnostic changes were apparent among the boys.

Short stature at presentation and outcome-Subjects' heights at follow up were compared with norms supplied by the survey of heights and weights of adults in Great Britain. ${ }^{11}$ Overall a poorer outcome was significantly more likely in children with anorexia nervosa who were taller at presentation $(p<0.05)$. At follow up five of 23 anorexia nervosa subjects $(22 \%)$ had heights that were less than two standard deviations from the norm for their age. Only one of these cases was short at presentation. For the four food avoidance cases there was no association between height at presentation and poor outcome. Only one case of food avoidance at follow up had a height less than two standard deviations below the norm. There were no significant differences in the length of follow up time between cases with short stature and those of normal height in either clinical group.

Weight at presentation and outcome-Of the 19 cases who were clinically wasted at presentation, six (32\%) were rated as having had a good outcome, four $(21 \%)$ as having had an intermediate outcome and seven $(37 \%)$ as having had a poor outcome, with three $(20 \%)$ in whom the outcome was not known. Outcome was therefore not significantly related to being wasted at presentation.

Association between background factors and outcome - There were no significant associations between poor outcome for either clinical group at follow up and any of the following background factors: presence of depression at presentation, age at onset, social class, family size, divorced parents, ordinal position of the child, length of stay in hospital, inpatient treatment, or multiple admissions to hospital. Obsessional features at presentation were, however, significantly more common among those with anorexia nervosa who had poor outcomes.

Association between clinical features at follow up and outcome-The relative contribution of the five Morgan-Russell subscales to the general outcome score for both clinical groups is shown in table 3. For cases of anorexia nervosa the contribution to poor outcome derives from all five subscales (nutritional status, menstruation, mental state, psychosexual, and socioeconomic). The trend of scores for the subscales for eating difficulties suggests that poor outcome is associated with all subscales except psychosexual.

Finally, there were no significant differences at follow up in any of the findings for children who presented above or below 12 years of age in any of the clinical groups.

\section{Discussion}

This study provides confirmation that anorexia nervosa does occur in young people before the onset of puberty. In this sample the youngest patient was 8 years of age at presentation suggesting that her disorder may have started some months before she was 8. No study has yet reported the onset of anorexia nervosa before the age of 7 .

The cross sectional results are of some interest, but their interpretation must be conservative because

Table 2 Number $(\%)$ of patients with anorexia nervosa $(n=23)$ and food avoidance emotional disorders $(n=18)$ who had good, intermediate, or poor outcomes at follow up according to the Morgan-Russell general outcome scale

\begin{tabular}{|c|c|c|c|c|c|c|}
\hline & \multicolumn{2}{|c|}{ Good outcome } & \multicolumn{2}{|c|}{ Intermediate outcome } & \multicolumn{2}{|c|}{ Poor outcome } \\
\hline & $\begin{array}{l}\text { Anorexia } \\
\text { nervosa } \\
(n=7)\end{array}$ & $\begin{array}{l}\text { Food } \\
\text { avoidance } \\
\text { emotional } \\
\text { disorders } \\
(n=11)\end{array}$ & $\begin{array}{l}\text { Anorexia } \\
\text { nervosa } \\
(n=7)\end{array}$ & $\begin{array}{l}\text { Food } \\
\text { avoidance } \\
\text { emotional } \\
\text { disorders } \\
(n=4)\end{array}$ & $\begin{array}{l}\text { Anorexia } \\
\text { nervosa } \\
(n=9)\end{array}$ & $\begin{array}{l}\text { Food } \\
\text { avoidance } \\
\text { emotional } \\
\text { disorders } \\
(n=3)\end{array}$ \\
\hline Boys & $2(29)$ & $3(27)$ & $4(57)$ & 0 & 1 (11) & 0 \\
\hline Girls & $5(71)$ & $8(73)$ & $3(43)$ & $4(100)$ & 8 (89) & $3(100)$ \\
\hline
\end{tabular}


Table 3 Mean scores of the Morgan-Russell subscales for the general outcome for anorexic $(n=18)$ and food avoidance emotional disorder $(n=17)$ groups*

\begin{tabular}{|c|c|c|c|c|c|c|}
\hline & \multicolumn{2}{|c|}{ Good outcome } & \multicolumn{2}{|c|}{ Moderate outcome } & \multicolumn{2}{|c|}{ Poor outcome } \\
\hline & $\begin{array}{l}\text { Anorexia } \\
\text { nervosa } \\
(n=5)\end{array}$ & $\begin{array}{l}\text { Food } \\
\text { avoidance } \\
\text { emotional } \\
\text { disorders } \\
(n=10)\end{array}$ & $\begin{array}{l}\text { Anorexia } \\
\text { nervosa } \\
(n=6)\end{array}$ & $\begin{array}{l}\text { Food } \\
\text { avoidance } \\
\text { emotional } \\
\text { disorders } \\
(n=4)\end{array}$ & $\begin{array}{l}\text { Anorexia } \\
\text { nervosa } \\
(n=7)\end{array}$ & $\begin{array}{l}\text { Food } \\
\text { avoidance } \\
\text { emotional } \\
\text { disorders } \\
(n=3)\end{array}$ \\
\hline Menstrual function & $11 \cdot 0$ & $10 \cdot 4$ & 6 & 9 & $1 \cdot 3$ & $2 \cdot 7$ \\
\hline Mental state & $11 \cdot 2$ & $10 \cdot 8$ & $8 \cdot 7$ & 7 & 8 & $5 \cdot 3$ \\
\hline Psychosexual & $10 \cdot 8$ & $11 \cdot 4$ & $6 \cdot 3$ & $7 \cdot 5$ & $5 \cdot 7$ & $9 \cdot 5$ \\
\hline Socioeconomic & 9.8 & $9 \cdot 6$ & $9 \cdot 4$ & 7.9 & $7 \cdot 2$ & $3 \cdot 0$ \\
\hline
\end{tabular}

*Based on direct interview of 35 subjects.

of the well known problems of the reliability and validity of retrospective collection of data from casenotes. We used comparison groups in an attempt to minimise any overemphasis of associations that may have been present between cases of anorexia nervosa and individual and family information at the time of presentation.

The lack of any significant differences among the groups in terms of family structure therefore suggests that such factors hold no specific meaning in anorexia nervosa. Of some interest, however, is the suggestion that life events that disrupt family life and permanently alter the families' status quo are significantly more common in anorexic families than emotional disorders without food avoidance but not those presenting with food avoidance. The trend of the results suggests that children identified as having food avoidance emotional disorders but who do not meet the criteria for anorexia nervosa seem to have an intermediate disorder (between anorexia nervosa and food avoidance) on the background characteristics we examined. We know of no studies that have examined the psychopathology of eating in childhood. We therefore cannot be sure of the nature of these cases. The recent reporting of a partial syndrome of anorexia nervosa ${ }^{13}$ where there are some, but not all, of the criteria for diagnosis suggests that in some cases eating difficulties in childhood may reflect a more serious psychopathological issue than has hitherto been considered.

Results of the follow up study suggested that the overall outcome for children with anorexia nervosa is not good. In this study the nature, course, and outcome of early onset anorexia nervosa were similar to those of adult cases. ${ }^{14}$

The follow up interviews suggested that some of the subjects remained preoccupied about food and weight in general although they no longer met the criteria for anorexia nervosa. For example, one man in his late 20s had become concerned that his 9 month old son was becoming fat even though there was no evidence for this. Perhaps recovered anorexics return to a pool of the population who have abnormal concerns about weight and food.

A further finding was that the outcome may be somewhat better for boys than girls; the reasons for this are not clear. There were no important differences between the sexes in any of the variables relating to presentation or outcome. Our social measures are of course substantially restricted by the study design. Perhaps this and the intrinsic psychological and physiological differences between boys and girls may account for the differences in overall outcome. The suggested finding and subsequent interpretation require further investigation.

Two boys were diagnosed as having physical disorders after initial treatment for anorexia nervosa. Clearly the misdiagnosis of a treatable physical disorder such as coeliac disease should be avoided. It should not be assumed, however, that the presence of such a diagnosis precludes a concurrent psychiatric syndrome related to food avoidance. For example, anorexia nervosa has been reported in the presence of cystic fibrosis and its occurrence in adults with diabetes mellitus has often been noted. ${ }^{15}$

The associations between weight and height are of interest. Being tall at presentation seems to indicate a poorer outcome at follow up. It may be that being taller at presentation sensitises these children to concerns about their body image. There is also the suggestion that it is the continued presence of self starvation that is producing short stature in some adults with early onset anorexia nervosa. These findings emphasise again the critical clinical issue of reinstituting a normal diet in young patients with anorexia nervosa.

The methodological limitations of this longitudinal study require some comment. Firstly, the length of 
follow up is variable. Secondly, there are differences in rate of development at the time follow up interview; both these factors may influence the outcome scores. Poor outcome, however, was not correlated with the duration of follow up time, but nevertheless these findings must be interpreted with caution.

Bryant-Waugh et al $^{6}$ reported a number of background factors associated with poor outcome among children with early onset anorexia nervosa. These include family factors (one parent families, step parents, and three or more generations living in the same house), depression in the child at presentation, long or multiple admissions to hospital (or both), and a younger age of onset. None of these factors, however, are significantly associated with poor outcome in anorexia nervosa cases in this study.

Clinical findings in the follow up subjects indicate that obsessionality at presentation was associated with a poor outcome for cases of anorexia nervosa but depression at presentation was not. These findings are not surprising in view of the evidence that suggests that obsessional symptoms in children show pronounced continuity into adult life. ${ }^{16}$ This suggests a rather non-specific but adverse role for obsessional features in anorexia nervosa. There seems to be no increased risk to the overall outcome for children whose onset of disorder is below the age of 12. Age 'cut off' is not the same as investigating the effects of puberty. Nevertheless, the results suggest little influence of puberty on the outcome.

The natural course and outcome for food avoidance emotional disorders seems more uncertain than would be predicted from a diagnosis of childhood emotional disorder with anxiety and fearfulness. Their overall outcome, however, seems to be better than that of early onset anorexia nervosa. Some of these patients may have been depressed, and some may represent the partial syndrome of anorexia nervosa recently described in reports of adult onset disorders.

We thank Professors Gerald Russell and Gethin Morgan for their assistance at various stages of this project. Both Professor Russell and Dr Peter Cooper provided invaluable comments during the preparation of this manuscript.

\section{References}

${ }^{1}$ Blitzer J, Rollins N, Blackwell A. Children who starve themselves: anorexia nervosa. Psychosom Med 1961;23:369-83.

2 Lesser L, Ashenden BJ, Debuskey M, Eisenberg L. Anorexia nervosa in children. Am J Orthopsychiatry 1960;30:572-80.

3 Warren W. A study of anorexia nervosa in young girls. J Child Psychol Psychiatry 1968;9:27-40.

4 Jacobs B, Isaacs S. Pre-pubertal anorexia nervosa: a retrospective controlled study. J Child Psychol Psychiatry 1986;27:237-50.

${ }^{5}$ Fosson A, Knibbs J, Bryant-Waugh R, Lask B. Early onset anorexia nervosa. Arch Dis Child 1987;62:114-8.

6 Bryant-Waugh R, Knibbs J, Fosson A, Kaminski Z, Lask B. Long term follow up of patients with early onset anorexia nervosa. Arch Dis Child 1988;63:5-9.

7 Russell GFM. Delayed puberty due to anorexia nervosa of early onset. In: Darby PL, Garfinkel PE, Garner DM, Coscina DV, eds. Anorexia nervosa: recent developments in research. New York: Alan R Liss, 1983:331-42.

8 Russell GFM. Anorexia nervosa: its identity as an illness and its treatment. In: Price JH, ed. Modern trends in psychological medicine. London: Butterworth, 1970:131-62.

9 Tanner JM, Whitehouse RH, Takaishi M. Standards from birth to maturity for height, weight, height velocity, and weight velocity: British children 1965, part I. Arch Dis Child 1966;41: 454-71.

10 Tanner JM, Whitehouse RH, Takaishi M. Standards from birth to maturity for height, weight, height velocity and weight velocity: British children 1965, part II. Arch Dis Child 1966;41: 613-5.

11 Rosenbaum S, Skinner PK. A survey of heights and weights of adults in Great Britain in 1980. Ann Hum Biol 1985;1:1-22.

12 Morgan HG, Russell GFM. Value of family background and clinical features as predictors of long-term outcome in anorexia nervosa: a follow up study of 41 patients. Psychol Med 1975;5:355-71.

${ }^{13}$ Mann AH, Wakeling A, Wood U, Monke E, Dobbs L. Screening for abnormal eating attitudes and psychiatric morbidity in an unselected population of 15 year old schoolgirls. Psychol Med 1983;13:573-80.

14 Hsu LK. Outcome of anorexia nervosa: a review of the literature. Arch Gen Psychiatry 1980;37:1041-6.

15 Szmuckler GI. Anorexia nervosa and bulimia in diabetics. J Psychosom Res 1984;28:365-9.

16 Zeitlin $\mathrm{H}$. The natural history of psychiatric disorder in children. Maudsley monographs, No 29. Oxford: Oxford University Press, 1986.

Correspondence to Dr IM Goodyer, Department of Psychiatry, University of Cambridge, Addenbrooke's Hospital, Cambridge CB2 2QQ.

Accepted 5 September 1988 